\title{
RECOMMENDED CHANGES IN THE USE OF THE LANGUAGE LABORATORY IN FOREIGN LANGUAGE PROGRAMS 1
}

\author{
by Klaus A. Mueller
}

For various reasons some serious misconceptions exist concerning the role of the language laboratory in foreign language instruction. These misconceptions stem in part from some rather widespread misunderstandings of the potentials and functions of laboratories. I would like today to highlight a number of areas in which some new or modified uses of the lab may help to implement and support foreign language courses. In addition, if time permits I shall discuss some aspects of laboratory functions closely related to new instructional modes and teaching materials.

Revised curricula and changing teaching practices are the primary reasons which necessitate changes in the use of the language laboratory. It is altogether apt that changing motivational factors of language learrers and revised objectives of instruction suggest that adjustments in the function and uses of the laboratory be made. These changes are also most likely to parallel charges in teaching modes.

Suggestions for more effective uses of the laboratory have recently been made. They are made, moreover, by those who not so long ago advocated the installation of laboratories and earlier characterized such laboratories as the panacea for under-achievers in foreign languages. Teachers as weli as administrators were among those advocates. These suggestior.s concern themselves with finding a better instrumentality with which to implement rew instructional modes and to use new machines as well as to modify the roles which teachers perform in the course of instruction. To my knowledge very little has yet been done to devise and implement strategies to accommodate the changing needs.

Before suggesting some specific alternative laboratory roles and modified uses of machines, I should like to caution that no new teaching and learning principles ever entirely replace old ones. The ALM approach, its beginnings and subsequent modifications, provides a convenient example of what I have in mind. We must be prepared at any given time to deal with several tendencies and theories, as well as with dreams and realities. Few of us would wish to live and work in

1This paper was given at the Fall Conference of the National Association of Language Laboratory Directors at Lone Mountain College, San Francisco, 16 October 1971. 
an epoch in which all was oriented according to one single concept and one uniform procedure.

The foreign language professor has never lacked in diversity of opinions regarding its aims and principles. For this reason, if for no other, it can safely be predicted that individualized instruction, as one example of innovation, will represent a major breakthrough in instructional and learning procedures, and it will henceforth affect our teaching. At the same time, however, it will not be considered the final answer to all our problems. Previous approaches and future emerging alternatives will continue to determine our methodology. The stereotype of the laboratory as a place to relieve the "burder.s of the overworked classroom teacher" has run its course. So has its mystique of catering to a "selective patronage."

The language laboratory will at times become the focal point of instruction. At other times it will function merely as a minor adjunct. In some instances it will be ignored. Today several new teaching practices demand changes in the roles the laboratory is capable of performing. Let me mention a few.

Among the innovations demanding changes are flexible scheduling, individualized instruction, programmed instruction, new teaching techniques, and especially the concept of practice versus contextual learning as described recently by Jarvis and Hatfield in Ohio and Indiana ${ }^{2}$; listening comprehension as a teaching strategy exemplified in the "audio-motor unit," so identified and described by Kalivoda, Morain and Elkins in Georgia3; the pleas for irterdisciplinary experimentation in all areas of language teaching, as an example, made by Eugene Briere of the University of Southern California, in which he differentiates between achievement and proficiency in foreign language performance 4 . The examples just cited are among some of the more notable suggestions being advanced. The recommendations with reference to the laboratories made recently in three ERIC focus Reports on The Teaching of Foreign Languages (numbers 13, 14 and 18) offer significant information and suggestions 5 . The first (13), by Turner of North Carolina, is entitled "Correlation of Language Class

2Gilbert A. Jarvis and William N. Hatfield, "The Practice Variable: An Experiment," Foreign Language Annals, 4, No. 4 (May 1971).

3Theodore B. Kalivoda, Genelle Morain, and Robert J. Elkins, "The Audio-Motor Unit: A Listening Comprehension that Works," Foreign Language Annals, No. 4 (May 1971).

4Eugene J. Briere, "Are We Really Measuring Proficiency with Our Foreign Language Tests?" Foreign Language Annals, 4, No. 4 (May 1971).

SERIC, Focus Reports on the Teaching of Foreign Languages. No. 13, 14, 18. 


\section{Recommended Changes}

and Language Laboratory." The second (14), by Stack, describes and reviews the mechanical potential of the language laboratory. And the last (18), by Arendt of Minneapolis, outlines some new scheduling patterns and the role of the foreign language teacher in changing times.

All these are recent documents, events and studies which are bound to have an effect upon the role the laboratory is to perform in the future. As I warned at the outset, all changes are necessarily partial in nature and no one philosophy or teaching mode holds sway completely at any given time. Having now alluded briefly to some recent suggestions for change, I would like to discuss a few lab functions which seem to be overdue when we consider present instructional realities.

First, the language laboratories will need to be used much more extensively as diagnostic centers. We are at present placing students in courses and sequences rather inefficiently, and are determining the articulation of programs poorly. The analysis and content of lexical and structural elements in testing and performance objectives in pronunciation, stress and intonation can be accomplished efficiently and effectively in the language laboratory rather than by other procedures. As you may know there exists a high degree of correlation between grade point average and foreign language achievement in a number of pre-tests such as the SAT Verbal and English Composition, and in performance in other subjects. I believe it is in the area of diagnosis, that the lab can play a new role and at the same time justify its demand for up-to-date machines and attractive learning environments. Diagnosis, particularly student self-diagnesis, seems to offer the greatest promise. Students at every level, but especially at high school and beyond, are vitally interested in discovering for themselves what their competencies are. A number of foreign language proficiencies can be tested effectively in the laboratory. Not only audiolingual skills, but also reading and writing, can be tested, specifically in items in which the stimulus or the response involves the use of the machines.

My second recommendation is that laboratories should be organized in somewhat different ways to accomplish individualized instruction. In both the high school and the college, typically a student working in the lab in which individualized instruction material is offered will find that he is at a definite disadvantage compared to the stucent who takes the regular course and reports to the lab in order to get practice in listening pronunciation, correction forms, and the like. $\mathrm{He}$ is at a disadvantage in the main because most of our laboratories are not ready to accommodate any given number of students at any one time for a specific program - and especially for that part of the 
program demanded by the student. The need for greater flexibility is absolutely essential. As an example, any student must be able to work with a given set of materials, such as a dialogue of the lesson, at wide and reasonable choices of dates and times. If this is possible then the laboratory serves its purpose. On the other hand, the student will most likely be discouraged to work in the lab if he is told that only two copies of the tape are available now and that there are thirty students waiting their turn. or that it will take approximately three to four hours until he will have an opportunity to work with it. He may even be told to come back on another day when the demand for this particular tape is not as great. Such situations are, of course, counter-productive.

A further recommendation also concerns individualized instruction. Since the student determines the emphasis and pace of instruction in this learning mode, he will require various parts of the recorded materials with differing emphasis on speaking, reading, and writing as his own needs dictate. Such students and course materials place additional demands on laboratory functions in order to accommodate students in regular courses - let's say German 1, 2, 3, 4-for certain pre-scheduled recorded lesson components, and in addition provide the flexibility for those students who need to work on a given lesson but are interested in only a portion of that lesson or in a specific aspect of the language which has not been pre-programmed in the traditional manner. Obviously the self-pacing of students, which is such a prominent and essential feature of individualized instruction may be greatly facilitated through work in the laboratory. As one example of somewhat different programming and functions, suffice it to mention that in individualized instruction, as well as in programmed materials, the laboratory needs to present a great variety of material which is pre-recorded and so designed as to engage students in branching as well as linear learning activities. Such facilities are in general not built into our laboratories as they presently exist.

A further need is the greater amount of tapes which offer materials on advanced levels. We are in most instances well equipped with lab materials from authors and publishers containing basic language materials to accompany beginning courses. We at times receive and have additional materials available of cultural or literary nature which are integrated into courses, and there is a growing amount of recorded materials available from various sources, such as foreign radio and television programs, cultural broadcasts on various subjects, and the like. These tapes, however, are not available in most laboratories today in attractive and readily accessible packages which would entice students to come to the lab and listen to them. One needs to employ special devices to accomplish this such as announcements on bulletin 


\section{Recommended Changes}

boards proclaiming "Come and see what the lab can do for you," and a listing of lab "menus." At the same time, having advertised them, it is important that these tapes are then available in sufficient quantities.

The next point concerns the flexibility of scheduling and supervision. The interest by students in working in the laboratory varies in direct proportion to the attention which is given these students, as well as the ready availability of the material which is in demand. Presently, guidance available to students in most laboratories is minimal. The student in scme of cur courses is receiving help and in some cases is asking for it, but in most instances he is not sufficiently motivvated to go on with recorded materials and work in the lab because the only real help available to him is on the mechanical level. A laboratory attendant will iscertain that the tape works and that the equipment is functioning.

A further important aspect is that our laboratories must become more joyful places and more attractive to work in. Many of our labs are located in places which are windowless and are in basements of buildings to which even the approach discourages the student from setting foot in it. Too mary of our laboratories are still plagued by recurring mechanical failures.

Perhaps the greatest criticism which can be levelled against the use of the laboratory is the lack of real concern on the part of teaching staffs for the functions and purposes the lab can perform. Those entrusted with guiding the language program must be expected to take an active part in the laboratcry program. We have examples of excellent cooperation in this respect in some schools, but in most cases, in my experience, new ways will have to be found. In the context of individualized instruction for instance, Arendt suggests in his ERIC report (number 18) that many of these problems will be solved by the publishers realizing the potential of new instruction programs and by supporting these with their "corsiderable financial rescurces." 6 He implies that this would include the production of all sorts of materials for the language laboratory, as well as for the classroom.

The actual situation is, unfortunately, very different. We are living in a time of tremendous economic stringency and publishers, although they may realize the potential of new programs, are certainly not supporting them aggressively. Publishers generally are taking a wait-and-see attitude. As an example, I can cite that with all the attention that the profession is at the moment placing on individualized instruction, and with the interest which has been generated on

GIbid., 18. 
this subject at various recer.t confererces, publications, and in the journals including the Encyclocedia Britannica Review of Foreign Language Learning, volume 2, only one program has to date been published. Publishers will wait until one level of even this program has produced sufficient sales before considering publication of the next level. This, of course, makes the implementation of new courses extremely difficult. We simply cannot count on the publishers support or on the publishing business as a whole to help us.

Thus students in new courses or students pursuing courses of a more traditional nature will demand more, and the language laboratory will have to find a way to supply the needs of this growing group of students who are interested not only in speaking, but in reading, writing and in literature. As was mentioned previously, mechanical failures still plague laboratories. And some more complex facilities originally offered are being gradually withdrawn as they lie unused or inoperative. At the same time the number of positions which allow recording by students are no longer maintained as they were originally designed, in spite of the fact that with new instructional techniques it is precisely this function which should be strengthened.

Any laboratory should I believe, have an attractive entrance or waiting room in which a student entering the lab is encouraged and enticed to engage in activity which he had perhaps not originally intended to utilize. Many devices, such as lists of available programs, suggestions for techniques for listening, suggestions on how to work with material, which would not necessarily occur to all students at all times, should be available. In addition, laboratory personnel should be accessible who would be willing to discuss such matters. Although the need for these more individual uses of the lab is great and growing, the need for pre-programmed and scheduled activities, such as we have had in the past, continues. As an instance we see today a tremendous interest by students for individualized instruction. But we find, on the other hand, a substantial number of students who consciously and deliberately avoid this particular approach. They are emotionally or for other reasons inclined to prefer lock-step learning procedures and more traditional classroom aspects, in which they arc forced, or at least urged, to appear at certain times, to take tests, and in general face the traditional penalties for non-attendance and the like. These students expect mid-term and final tests, as well as quizzes and expect to be told when to go to the lab, what to do there, how long to stay, and are frequently required to return an attendance slip to prove to the instructor that they have actually attended the laboratory. These students must continue to be served. To put it another 


\section{Recommended Changes}

way, we must consciously and consistently provide language instruction material in the lab for any level and for all learning modes.

In conclusion, let me say that in addition to providing this new flexibility and attractiveness of our laboratories, it is necessary for teachers in our profession to give the lab new support and to make suggestions as to how the laboratory can be used most effectively. New recordings and lab activities which support or implement instructional innovations need to be developed with the full understanding of what can and cannot be expected to be accomplished in the laboratory. As an instance, there are a number of tapes now in existence which would have to be listened to by the student perhaps five hundred times before he can reasonably comprehend what is on the tape or what is asked of him as a response. Such tapes are useless. Other tapes, however uniquely and imaginatively implement material which a textbook cannot contain - in other words, materials the student can find in no other place than the language laboratory. As an example, there is a recent publication on a beginning literature level in German which has a tape program which supplements the literary selection in the textbook by providing listening comprehension through a recorded series of short, spontaneous conversations by experts on the various literary perioc's and selections to which students listen until they have attuned their ears to the speakers' speech habits and comprehend what they have said. 7 Since the ultimate purpose of listening resides in the comprehension of ideas, the speakers recorded in this program have been selected for their impressive knowledge of German literature and their total commitment to the interpretation of ideas. No effort is being made to correlate with the interpretation given in the text, and no effort by the speakers is made to speak slowly or to simplify the language. The student listens to the conversation repeatedly until he has comprehended the material well enough to answer questions and to discuss the ideas presented. Although this is not an easy task, it is certainly a valuable and necessary one. Again, as discussed in previous aspects of this paper, the ultimate value of this type of tape program will depend on the willingness of the course instructor to integrate the taped materials into his total program.

7Edward Diller, Roger A. Nicholls, and James R. McWilliams, Meisterwerke der deutschen Sprache (New York: Random House, 1970). 